\title{
A TEMÁTICA MIGRATÓRIA NA REVISÃO PERIÓDICA UNIVERSAL DOS EUA: OPORTUNIDADE POLÍTICA DIANTE DO HEGEMON
}

Matheus de Carvalho Hernandez ${ }^{\mathrm{a}}$

aé professor de Relações Internacionais da Universidade Federal da Grande Dourados. Dourados,

MS, Brasil.E-mail: matheuschernandez@gmail.com

Orcid: 0000-0003-3384-4982

William Torres Laureano da Rosa ${ }^{b}$

bé professor de Relações Internacionais no Programa de Pós-Graduação em Relações Internacionais

San Tiago Dantas (Unesp/Unicamp/PUC-SP). São Paulo,SP, Brasil.E-mail: wlaureano@gmail.com

Orcid: 0000-0003-3113-723X

http://dx.doi.org/10.1590/0102-065100/108

\section{Introdução}

O Conselho de Direitos Humanos (CDH), criado em 2006, e seu mecanismo de Revisão Periódica Universal (RPU) representam uma das maiores novidades no campo institucional da Organização das Nações Unidas (ONU) dos últimos tempos. Por meio da RPU, práticas e políticas de direitos humanos de todos os Estados-membros da ONU passam pelo escrutínio de seus pares ao longo de ciclos de quatro anos e meio. O Estado revisado é alvo de recomendações dos demais membros e tem a obrigação de reagir a cada uma delas, expressando seu aceite ou recusa a elas. Dessa forma, os países, ao criarem a RPU, pretenderam responder à tradicional acusação de "politização" do sistema de direitos humanos forjando um mecanismo universal pelo qual todos os Estados passam, 
independentemente do seu poder, dos seus recursos e da importância que ocupam na realidade internacional.

No que tange aos Estados Unidos, as diferentes administrações mantiveram uma tensa relação com o CDH, especialmente as republicanas de Bush e Trump. Na tentativa de contribuir com esse campo, este artigo integra uma agenda de pesquisa mais ampla que pretende cobrir variados aspectos da participação dos EUA na RPU, seja como país revisado ou como país revisor.

Os esforços dessa agenda que precederam o presente artigo cobriram diversos aspectos da relação entre EUA e $\mathrm{CDH}$, como a tensa relação do governo Bush com o Conselho, que não só votou contrariamente à sua criação em 2006, mas também decidiu não integrá-lo como membro e o boicotou financeiramente (Hernandez, Albres e Macedo, 2013); a decisão do governo Obama de voltar a participar ativamente de seus debates e procedimentos, inclusive da RPU (Hernandez e Rosa, 2018); o incremento da tensão no governo Trump, que rompeu recentemente com o órgão (Hernandez, 2017a, 2018); e, por fim, um mapeamento panorâmico dos dois ciclos da RPU pelos quais os EUA, como país revisado, passaram durante o governo Obama, em 2010 e 2015, respectivamente (Hernandez e Rosa, 2018).

Uma vez verificado o engajamento dos EUA e sua participação de maneira mais global, o próximo passo desta agenda, ainda muito pouco explorada pela literatura, é examinar esse comportamento em temas específicos. Para tanto, elegemos o tema das migrações como alvo. Explicitaremos as motivações metodológicas desta escolha mais adiante.

Vários relatórios internacionais mostram que há problemas na forma como as estruturas estatais estadunidenses tratam migrantes. As violações abundam. São recorrentes, por exemplo, os problemas relacionados à detenção de migrantes, sem direito ao devido processo legal ou acesso a um advogado nos processos de solicitação de asilo (Canada, 2018), 
e com denúncias de que essas detenções não somente têm sérios problemas de legalidade, mas também são mantidas por um longo período de tempo e com padrão abaixo do aceitável por essas agências (Global Detention Project, 2010; Inter-American Commission on Human Rights, 2010). Essa situação de detenção chegou, inclusive, às denúncias realizadas pelo Fundo das Nações Unidas para a Infância (Unicef) sobre o tratamento dispensado às crianças que fogem de situações de violência, mostrando como elas são presas e separadas de seus pais por autoridades migratórias, para depois serem deportadas (US and Mexico..., 2018).

O texto se organiza a partir de uma primeira seção a respeito da agenda de pesquisa mais ampla na qual este artigo se insere e da apresentação das hipóteses que o norteiam. A segunda seção trata do fluxo migratório para os EUA, notadamente daquele advindo do México e do chamado Triângulo Norte (Guatemala, Honduras e El Salvador). Nesta segunda seção, discutimos ainda a relação entre migração indocumentada para os EUA, especialmente dos países - acima mencionados - que são o foco deste estudo, e a ajuda externa, variável importante para discussão das hipóteses extraídas de Terman e Voeten (2018). Segundo essas hipóteses, sobre as quais trataremos com detalhes mais adiante, a RPU é orientada por uma lógica relacional politicamente mediada, a qual seria explicativa tanto da decisão de fazer uma recomendação ou não por parte do Estado revisor e o perfil dessa recomendação quanto da decisão de acatar ou não tal recomendação por parte do Estado revisado. A terceira seção dedica-se justamente à discussão dessas hipóteses, apontando para a validade da explicação para o funcionamento sistêmico da RPU, mas sugerindo a necessidade da consideração de uma variável explicativa específica - o número de migrantes indocumentados - em relação às peculiaridades do tema migratório na RPU. 
Além de apontar a dificuldade da explicação generalizante de Terman e Voeten em relação à temática migratória, o que é reconhecido pelos próprios autores, o olhar detido sobre essa temática evidencia como a própria lógica aliado $\times$ não-aliado, da qual esses autores se valem, pode ser pouco iluminadora. Isso porque, como veremos, o perfil dos Estados que mais recomendam aos EUA quando se trata de migrações e que têm mais recomendações recusadas atende muito mais a uma lógica dinâmica de interesses divergentes diante das práticas e políticas estadunidenses concernentes aos migrantes indocumentados do que a uma caracterização como aliado e não-aliado. A iluminação dessa questão, inclusive, demonstra como a RPU, quando se trata do fenômeno migratório, é mais do que simplesmente um espaço de exercício de shaming, enquadramento normalmente dado pela literatura de direitos humanos ao mecanismo e no qual Terman e Voeten também se inserem de modo peculiar. Aos olhos deste artigo, a RPU é, sim, um espaço institucional de oportunidade política do qual os atores se valem - inclusive os menos poderosos - para colocar suas agendas diante da principal hegemonia, ou seja, os EUA.

\section{Trajetória da pesquisa e elaboração do desenho}

Por meio de análise anterior dos dois ciclos pelos quais os EUA passaram na RPU (2010 e 2015), percebemos alguns dados gerais com potencial heurístico: apesar da participação inexistente dos EUA como revisor nas quatro primeiras sessões da RPU (três delas durante o governo Bush e uma delas poucos dias depois de Obama retornar ao órgão), o país rapidamente se tornou ativo durante o governo Obama (Hernandez e Rosa, 2018). Segundo os dados utilizados, em 2017 os EUA já eram, em comparação aos outros membros permanentes do Conselho de Segurança da ONU, o segundo país a fazer mais recomendações na história do Conselho de Direitos Humanos, tendo ultrapassado o Reino 
Unido e ficando atrás apenas da França, um país fortemente engajado com esse mecanismo. ${ }^{1}$

Outro ponto interessante a refletir em relação ao aprendizado institucional dos EUA foi o crescimento das recomendações não aceitas por esse país quando comparados os dois ciclos. Enquanto no primeiro ciclo, em 2010, a taxa de rejeição ficou em 34,6\%, no segundo ciclo, em 2015, a taxa chegou a $54,8 \%$. O que se observa aqui é como, nos valendo das noções de Forsythe (2011), o dito cosmopolitismo wilsoniano que teria supostamente respaldado a decisão de Obama de colocar os EUA de volta no CDH (após o boicote de Bush), contexto do primeiro ciclo, logo cedeu lugar ao tradicional pragmatismo casuístico da política externa norte-americana, a se registrar no notável incremento de recomendações não aceitas já no segundo ciclo e, vale dizer, no mesmo governo Obama.

Sistematizamos também quais foram os temas mais tratados pelos Estados que recomendaram aos EUA durante os dois ciclos. Salta aos olhos a reincidência do tema "instrumentos internacionais", ${ }^{2}$ com 193 ocorrências $-28,9 \%$ de todas as recomendações feitas até hoje aos EUA (Hernandez e Rosa, 2018). A frequência dessa categoria deve-se ao fato de os EUA tradicionalmente não ratificar os tratados sobre o tema, apesar de ser força política historicamente importante na construção da arquitetura institucional do sistema internacional de direitos humanos da ONU (Hernandez e Rosa, 2011; Hernandez, 2013, 2017b).

Observando, entretanto, a listagem dos 56 temas ao longo dos dois ciclos de revisão pelos quais passaram os EUA, um dos mais reincidentes e o sétimo da lista (com 60

\footnotetext{
1 De acordo com os dados da UPR-Info, ao final de 2017 os EUA já haviam feito 997 recomendações, estando atrás apenas da França, com 1606.

2 O UPR-Info, ONG que se dedica à sistematização do mecanismo, apresenta uma categorização dos temas apresentados em cada RPU, totalizando 56 categorias diferentes.
} 
recomendações, o que representa quase $9 \%$ do total) nos chamou a atenção: migração, foco deste artigo.

Tabela 1

Principais temas das recomendações aos EUA nos dois ciclos da RPU

\begin{tabular}{|c|l|c|c|}
\hline Ranking & \multicolumn{1}{|c|}{ Categoria } & $\begin{array}{c}\text { Total de } \\
\text { recomendações }\end{array}$ & $\begin{array}{c}\% \text { das } 668 \\
\text { recomendações }\end{array}$ \\
\hline 1 & Instrumentos internacionais & 193 & 28,89 \\
\hline 2 & Direitos das crianças & 95 & 14,22 \\
\hline 3 & Direitos das mulheres & 86 & 12,87 \\
\hline 4 & Pena de morte & 83 & 12,43 \\
\hline 5 & Discriminação racial & 80 & 11,98 \\
\hline 6 & Detenção & 68 & 10,18 \\
\hline 7 & Migrantes & 60 & 8,98 \\
\hline
\end{tabular}

Fonte: Elaborada pelos autores, com os dados extraídos de UPR-Info (2018).

Um olhar detido sobre o desenvolvimento da temática migratória ao longo das duas revisões pelas quais os EUA passaram se justifica não só pela atualidade inescapável do tema e por sua importância histórica no ambiente político e social dos EUA, mas por sua natureza complexa na agenda de direitos humanos. Essa complexidade tem a ver com o fato de o tema migração, diferentemente de outras questões da agenda de direitos humanos, não permitir aos Estados desenvolvidos a tradicional posição discursiva de respeitadores de direitos humanos e de juízes moralmente superiores das práticas de direitos humanos dos países menos poderosos. Por si só, isso é relevante, tendo em vista que o $\mathrm{CDH}$, notadamente a RPU, se torna, conforme já ressaltado na introdução, mais do que um espaço de exercício de shaming, uma oportunidade política a partir da qual os atores, inclusive os menos poderosos, se valem para colocar seus interesses diante do país hegemônico do sistema.

Nesse sentido, há trabalhos que verificam que as organizações internacionais ensinam, promovem e difundem 
ideias e normas (Finnemore, 1993). A literatura vem apresentar que o processo de difusão de ideias e normas teria ajudado muitos países a desenvolver instituições políticas e a tornar os direitos humanos um tema de política doméstica, ao mesmo tempo em que permitiu que muitos aspectos e interesses convergissem (Jakobi, 2009, p. 4; Bearce e Bondanella, 2007). As organizações e os mecanismos internacionais criados por elas, como a RPU, criam esse espaço de socialização e de contato entre seus membros (Hasenclever, Mayer e Rittberger, 1997), possibilitando que os países possam, assim, colocar seus interesses perante outros países. Ainda que a convergência tenha sido o tema de maior atenção, a questão migratória conforme apresentada neste artigo analisa uma situação em que, em meio a um espaço de socialização institucional, não há convergência entre os interesses dos países de emigração e os interesses do país de imigração. No limite, a percepção é a de que a RPU é um espaço internacional normatizado no qual interesses divergentes dos EUA sobre a situação dos direitos humanos no plano doméstico estadunidense podem ser ouvidos e debatidos publicamente. Portanto, a RPU não deve ser enxergada apenas como uma chance que os países esperam para simplesmente constranger os EUA, mas, mais do que isso, ela deve ser vista como uma oportunidade política regrada mobilizada pelos Estados para avançarem suas agendas e demandas sobre os EUA.

Em meio à atualização da revisão de literatura sobre o mecanismo da RPU, um artigo em especial, da autoria de Rochelle Terman e Erik Voeten (2018), se destacou. O estudo, inserido na literatura sobre shaming, cobre as mais de 40 mil recomendações já feitas por todos os países nos dois primeiros ciclos da RPU. Os autores argumentam que a chamada politização do mecanismo, frequentemente 
apontada pela literatura sobre o $\mathrm{CDH}^{3}$ como um de seus principais problemas, não necessariamente debilita o funcionamento da RPU (Freedman, 2015). Mais do que isso, os autores evidenciam como a RPU é política por natureza e é da política, e não apesar dela, que ela deriva sua importância, pressuposto compartilhado também por este artigo (Terman e Voeten, 2018, p. 6).

Ser política nos termos de Terman e Voeten (2018) significa dizer que existe uma dinâmica relacional na RPU, ou seja, tanto a decisão pelo país revisor de tecer ou não uma recomendação ao país revisado quanto a decisão do país revisado de aceitar ou não uma recomendação proferida por um Estado revisor passam pela posição de aliado ou de não-aliado mantida pelos Estados em questão. O que percebemos é que a divisão entre aliados e não-aliados pode ser limitadora na análise do mecanismo. Antes, trabalhamos com a ideia segundo a qual há interesses opostos e convergentes que fazem com que os membros do $\mathrm{CDH}$ que participam da RPU tenham a oportunidade de colocar as suas agendas frente à potência.

Orientando-se pela tentativa de identificação de um Estado como aliado ou não de outro, os autores demonstram a seguinte hipótese: Estados aliados tendem a não fazer recomendações entre si no âmbito da RPU, porém, quando fazem, tendem a fazer recomendações mais brandas e vagas; assim, o país revisado, ao receber uma recomendação - geralmente branda - de um país aliado, tende a aceitá-la com mais facilidade; e a aceitação pelo Estado revisado deriva não apenas da natureza menos agressiva do conteúdo da recomendação em si, mas principalmente também por levar em conta que

\footnotetext{
3 É comum que as ONGs de direitos humanos também apontem a "politização" como um elemento que prejudica o funcionamento da RPU e do próprio CDH: "Maryam Al Khawaja, consultora especial de advocacy do Gulf Center for Human Rights e membro da diretoria do International Service of Human Rights, disse: 'A seletividade e politização da resposta do conselho às situações nos países permite que alguns governos escapem ao escrutínio de graves violações de direitos humanos"” (UN Human..., 2018, tradução nossa).
} 
um Estado aliado, zeloso da relação estratégica que mantém com o país revisado, só tece uma recomendação se realmente julgá-la prioritária. Assim, o Estado revisado, também interessado na manutenção da relação estratégica com o país revisor e, em virtude disso, impossibilitado de desqualificar o emissor da recomendação, tende a aceitá-la com mais facilidade.

A hipótese pode também ser formulada a partir de sua outra face: Estados não-aliados tendem a fazer mais recomendações entre si no âmbito da RPU e, ao fazê-las, tendem a tecer recomendações menos brandas e mais específicas; assim, o país revisado, ao receber uma recomendação geralmente mais incisiva - de um país não-aliado, tende a recusá-la com mais facilidade; e a recusa pelo Estado revisado decorre não apenas da natureza mais agressiva do conteúdo da recomendação em si mesma, mas principalmente por considerar que um país não-aliado tem menos amarras estratégicas para recomendar, na medida em que não precisa zelar tanto pela harmonia da relação em questão; assim, o Estado revisado, sem os constrangimentos também de ter que manter uma relação estratégica com o país revisor, pode recorrer inclusive ao expediente de desqualificar o emissor da recomendação, independentemente de seu conteúdo, e, assim, recusá-la com baixos custos políticos.

Por um lado, nossas pesquisas anteriores a respeito dos dois ciclos da RPU pelos quais passaram os EUA parecem corroborar em alguma medida as hipóteses de Terman e Voeten, ainda que as pesquisas tenham sido elaboradas anteriormente à publicação dos autores. Por exemplo: entre os dez países que mais fizeram recomendações aos EUA em seus dois ciclos na RPU, prevalecem de fato Estados normalmente considerados como não-aliados, como Venezuela (29 recomendações), Irã (21), Cuba (19), Bolívia (19), Coreia do Norte (16) e Rússia (14). Vale lembrar que vários desses Estados foram enquadrados como "eixo do mal" durante praticamente toda a gestão Bush por meio da sua "guerra ao terror". 
Tabela 2

Os dez países que mais realizaram recomendações aos EUA nos dois ciclos da RPU

\begin{tabular}{|c|l|c|c|}
\hline Ranking & Estado revisor & $\begin{array}{c}\text { Total de } \\
\text { recomendações }\end{array}$ & $\begin{array}{c}\text { \% das 668 } \\
\text { recomendações }\end{array}$ \\
\hline 1 & Venezuela & 29 & 4,34 \\
\hline 2 & Irã & 21 & 3,14 \\
\hline 3 & Cuba & 19 & 2,84 \\
\hline 4 & Egito & 19 & 2,84 \\
\hline 5 & Bolívia & 19 & 2,84 \\
\hline 6 & Coreia do Norte & 16 & 2,4 \\
\hline 7 & Áustria & 15 & 2,25 \\
\hline 8 & Rússia & 14 & 2,1 \\
\hline 9 & França & 14 & 2,1 \\
\hline 10 & Nicarágua & 13 & 1,95 \\
\hline
\end{tabular}

Fonte: Elaborada pelos autores, com os dados extraídos de UPR-Info (2018).

Por outro lado, uma vez que os EUA são o país que mais receberam recomendações na história da RPU (um total de 74688 recomendações) e que há alterações significativas entre o tipo de recomendação e seus emissores entre um ciclo e outro, a divisão aliado e não-aliado perde força. Antes, os dados da pesquisa corroboram o nosso argumento de que a RPU se constitui em uma oportunidade política institucionalmente legitimada para que os Estados possam avançar seus temas e agendas diante da potência hegemônica. Aquela dinâmica de aprendizagem institucional que mencionamos anteriormente não é pertinente apenas para compreender a participação crescente dos EUA como Estado revisor, manifesta no número de recomendações proferidas. Ela também é interessante para observar como os Estados também aprenderam a se valer do espaço da RPU para, como mencionado, avançar suas demandas diante dos EUA. Isso auxilia a compreender a posição do país como aquele que mais recebeu recomendações, pois as oportunidades de os Estados, especialmente os menos poderosos (os quais constituem a imensa maioria do sistema internacional), colocarem publicamente 
suas demandas, agendas e interesses diante dos EUA são raras, aumentando a significância política da RPU.

Esse dado também mostra como a RPU é nutrida por uma dinâmica política e relacional de fato, pois sendo ainda o centro da geopolítica global, os EUA interagem com praticamente todos os países do planeta, o que os leva a um lugar de extrema visibilidade ao participar da RPU, seja aos olhos dos muitos aliados (que também fazem recomendações, ainda que menos numerosas e mais brandas), seja aos olhos de vários países não-aliados (que se valem da RPU para criticar a situação dos EUA em matéria de direitos humanos).

Apesar dessas confirmações iniciais, as nossas pesquisas que antecedem a este artigo não testaram efetivamente as hipóteses de Terman e Voeten (2018). Diante disso e de nosso foco na questão migratória, na terceira seção compararemos de maneira sistemática a validade das referidas hipóteses sistêmicas em relação aos dados das duas revisões dos EUA. O propósito será verificar se as hipóteses se sustentam quando aplicadas à RPU dos EUA de (1) maneira geral e (2) especificamente sobre o tema migratório. Nosso ponto de partida será a discrepância já identificada entre a lista dos países que mais têm recomendações recusadas pelos EUA em matéria de migração (Honduras em primeiro e México e Guatemala empatados em segundo) e suas respectivas posições na lista dos países que mais têm recomendações recusadas pelos EUA de maneira geral $\left(74^{\circ}, 35^{\circ}\right.$ e $18^{\circ}$, respectivamente $)$.

Além desse ponto de partida contraintuitivo em relação à hipótese de Terman e Voeten e da inegável relevância histórica e atual da temática migratória para os EUA, a motivação para adoção detida dessa temática como foco deste artigo é de cunho metodológico e reforça a pertinência de testar as referidas hipóteses para esse fenômeno específico. Uma das características mais desafiadoras dos direitos humanos como tema da política internacional é seu potencial de colocar sob escrutínio internacional a forma como um 
Estado trata seus próprios cidadãos, ou seja, não se trata de um tema essencialmente da relação entre diferentes soberanias em um espaço anárquico, mas de um tema que permite que um ator externo incida sobre uma dimensão doméstica essencial da soberania: o tratamento dispensado a seus próprios cidadãos. Essa é a essência da RPU.

O tema da migração, enquanto item da agenda internacional de direitos humanos, entretanto, coloca uma camada adicional de complexidade, pois não se trata mais apenas de um Estado revisor poder se referir com legitimidade a respeito de como o Estado revisado trata seus nacionais. Trata também de como o Estado revisor pode reivindicar tratamento digno tanto aos seus nacionais quanto a nacionais de outros países que estão presentes como migrantes (documentados ou não) no território do Estado revisado. Portanto, é um fenômeno altamente relacional e entremeado de relações políticas e interesses divergentes, justificando-se, assim, a verificação da validade das hipóteses sistêmicas de Terman e Voeten (2018) para o tema. Os próprios autores, em meio a seus vários testes estatísticos de significância das variáveis, reconhecem a natureza peculiarmente contenciosa da temática migratória na RPU. Ao analisarem apenas as recomendações mais severas, ou seja, aquelas que demandam claramente mudança de comportamento do Estado revisado, afirmam:

nós descobrimos que as recomendações sobre "mulheres, crianças e tráfico" estavam entre as mais aceitas pelos Estados (16 pontos percentuais com maior probabilidade de serem aceitas), enquanto as que envolviam "migração" eram as menos prováveis de serem aceitas. De fato, entre as recomendações mais severas, as que envolvem questões de migração têm entre 12 e 14 pontos percentuais menos chances de serem aceitas. (Terman e Voeten, 2018, pp. 16-17, tradução nossa) 
Esse achado dos autores reforça nosso argumento acerca da singularidade da temática migratória nos debates e mecanismos internacionais sobre direitos humanos e, com isso, reforça a justificativa a respeito da necessidade de abordá-la de forma mais detida, ainda mais no caso dos EUA, um histórico receptor de migrantes.

\section{Migrações para os EUA: México e Triângulo Norte}

Verifica-se que, historicamente, há um maior fluxo migratório dos países da América Latina, em especial do México pela fronteira norte, para os EUA. Populações de outros países, como Honduras, El Salvador e Guatemala (o chamado Triângulo Norte), também têm utilizado essa rota terrestre. O peso das migrações do conjunto de países latino-americanos e caribenhos representa 25 milhões de migrantes, enquanto o segundo maior grupo, o asiático, é composto de 15 milhões. Desses 25 milhões, mais de 12 milhões são de migrantes originários do México (Radford e Noe-Bustamante, 2019). Com relação aos países do Triângulo Norte, condições socioeconômicas próprias têm gerado pressões migratórias nos países de origem, fazendo que com esse movimento ganhe destaque recente nos estudos sobre o tema (International Organization for Migration, 2018, p. 80). ${ }^{4}$

Tabela 3

Estimativa do número total de migrantes documentados e indocumentados ${ }^{5}$

\begin{tabular}{|l|c|}
\hline \multicolumn{1}{|c|}{ País } & Número total de migrantes nos EUA \\
\hline México & 12.680 .000 \\
\hline China & 2.420 .000 \\
\hline Índia & 2.310 .000 \\
\hline
\end{tabular}

(continua)

\footnotetext{
4 Ressalta-se neste contexto as caravanas de migrantes dos países do Triângulo Norte que, no final de 2018, se tornaram notícia por tentarem atravessar a fronteira entre México e Estados Unidos (Rojas, 2018; García, 2019).

5 Tendo em vista a dificuldade de se aferir com precisão a quantidade de migrantes indocumentados, justamente por sua condição indocumentada, optamos pelo uso do termo "estimativa" nas tabelas que tratam desse fenômeno.
} 
Tabela 3 (continuação)

\begin{tabular}{|l|c|}
\hline \multicolumn{1}{|c|}{ País } & Número total de migrantes nos EUA \\
\hline Filipinas & 2.080 .000 \\
\hline Porto Rico & 1.900 .000 \\
\hline Vietnã & 1.410 .000 \\
\hline El Salvador & 1.390 .000 \\
\hline Cuba & 1.250 .000 \\
\hline Coreia do Sul & 1.180 .000 \\
\hline República Dominicana & 1.070 .000 \\
\hline Guatemala & 980.000 \\
\hline Canadá & 890.000 \\
\hline Jamaica & 770.000 \\
\hline Colômbia & 750.000 \\
\hline Reino Unido & 750.000 \\
\hline Haiti & 670.000 \\
\hline Alemanha & 650.000 \\
\hline Honduras & 600.000 \\
\hline
\end{tabular}

Fonte: Elaborada pelos autores, a partir dos dados de Radford e Noe-Bustamante (2019).

Nas relações entre EUA e México especificamente, a expectativa de impedir o fluxo migratório é antiga, sendo os acordos do Nafta apontados como destaque (Johnson, 2000; Roldán, 2015). Mesmo com esses acordos, ${ }^{6}$ o fluxo migratório latino-americano para os EUA não diminuiu. Pelo contrário, estudos recentes mostram que uma conjunção de fatores, como a recessão econômica mexicana de 2012 (Villarreal, 2014), e a diminuição da pirâmide etária no México trouxeram como consequência o fato de que menos jovens estariam dispostos a emigrar para os EUA, e, com isso, abriram espaço para migrações de outros países, em especial as do Triângulo Norte (Selee, 2017, p. 3). Nesse sentido, a Tabela 4 mostra que a grande maioria dos migrantes que obtiveram a residência

6 Cf. Selee (2017) para uma compreensão melhor dos acordos entre EUA e México relacionados com o tema das migrações. 
legalmente nos EUA vieram, majoritariamente, da região do Caribe, especialmente do México, evidenciando que há, sim, a possibilidade de regularização migratória de pessoas oriundas dos países estudados.

Tabela 4

Número de migrantes que obtiveram residência nos EUA por região e país de origem

\begin{tabular}{|l|c|c|c|}
\hline Região ou país de última residência & 2015 & 2016 & 2017 \\
\hline Total & 1.051 .031 & 1.183 .505 & 1.127 .167 \\
\hline Europa & 90.789 & 98.043 & 89.706 \\
\hline Ásia & 405.854 & 442.854 & 404.371 \\
\hline América & 439.228 & 502.639 & 489.676 \\
\hline México & 157.227 & 172.726 & 168.980 \\
\hline Caribe & 146.086 & 180.479 & 173.724 \\
\hline Cuba & 54.178 & 66.120 & 64.749 \\
\hline República Dominicana & 50.382 & 60.613 & 58.384 \\
\hline Haiti & 16.787 & 23.185 & 21.501 \\
\hline Jamaica & 17.362 & 22.833 & 21.517 \\
\hline Outro Caribe & 7.377 & 7.728 & 7.573 \\
\hline América Central & 46.556 & 54.512 & 52.907 \\
\hline Costa Rica & 2.121 & 2.295 & 2.259 \\
\hline El Salvador & 18.699 & 21.268 & 21.920 \\
\hline Guatemala & 11.466 & 12.548 & 12.792 \\
\hline Honduras & 9.071 & 12.996 & 11.147 \\
\hline Nicarágua & 3.262 & 3.397 & 3.014 \\
\hline Panamá & 1.133 & 1.130 & 1.021 \\
\hline América do Sul & 70.049 & 75.571 & 75.595 \\
\hline África & 98.677 & 110.754 & 116.667 \\
\hline Oceania & 6.227 & 6.489 & 5.986 \\
\hline
\end{tabular}

Fonte: Elaborada pelos autores, a partir de dados do Department of Homeland Security (2018), com o número de pessoas que obtiveram a residência legalmente nos EUA divididos por região e por país de última residência.

A relevância dos países destacados para o contexto migratório dos EUA fica clara quando observamos o número de 
migrantes que recebem a autorização de residência por ano. Porém, mais do que o estoque geral de migrantes, um aspecto essencial do fenômeno migratório na relação entre os países é o número substancial dos chamados migrantes indocumentados, migrantes que não estão com sua situação formalmente regularizada no país receptor. Historicamente, a questão dos migrantes indocumentados contribui muito para que o tema migratório seja parte da agenda social e política estadunidense. Mais recentemente, encontramos os esforços da administração Trump para construção do muro na sua fronteira sul como forma de contenção da migração latino-americana, segundo a administração republicana. ${ }^{7}$ Com isso, o México e os países do Triângulo Norte ganham maior destaque. Historicamente, são os indocumentados que mais sofrem com acesso a direitos e com o estigma social diante da sua condição jurídica. Na Tabela 5, indicamos o ranking dos países de origem dos migrantes indocu80 mentados que vivem nos EUA. Segundo estudo de Bryan Baker (2017), publicado pelo Homeland Security, os países de origem do maior número de migrantes nessa situação são justamente México e os do Triângulo Norte.

Tabela 5

Estimativa do número de migrantes indocumentados nos EUA por país

\begin{tabular}{|l|c|c|c|c|}
\hline \multirow{3}{*}{\begin{tabular}{c}
\multirow{3}{*}{$\begin{array}{c}\text { País de } \\
\text { origem }\end{array}$} \\
\cline { 2 - 5 }
\end{tabular}} & \multicolumn{4}{|c|}{$\begin{array}{c}\text { Número estimado da população migrante } \\
\text { indocumentada em janeiro }\end{array}$} \\
\cline { 2 - 5 } & Número & Porcentagem & Número & Porcentagem \\
\cline { 2 - 5 } Total & 12.120 .000 & 100 & 11.780 .000 & 100 \\
\hline México & 6.640 .000 & 55 & 6.980 .000 & 59 \\
\hline El Salvador & 700.000 & 6 & 540.000 & 5 \\
\hline Guatemala & 640.000 & 5 & 500.000 & 4 \\
\hline
\end{tabular}

\footnotetext{
7 A ação do governo Trump em relação ao muro na divisa com o México, destacada promessa de campanha do republicano, foi alvo de disputa durante a aprovação do orçamento de 2019 e levou a uma das maiores paralisações de serviços públicos no país, chamado em inglês de "shutdown".
} 
Tabela 5 (continuação)

\begin{tabular}{|l|c|c|c|c|}
\hline \multirow{2}{*}{\begin{tabular}{c}
\multirow{2}{*}{$\begin{array}{c}\text { País de } \\
\text { origem }\end{array}$} \\
\cline { 2 - 5 }
\end{tabular}} & \multicolumn{4}{|c|}{$\begin{array}{c}\text { Número estimado da população migrante } \\
\text { indocumentada em janeiro }\end{array}$} \\
\cline { 2 - 5 } & Número & Porcentagem & Número & Porcentagem \\
\hline Índia & 430.000 & 4 & 220.000 & 2 \\
\hline Honduras & 400.000 & 3 & 280.000 & 2 \\
\hline Filipinas & 360.000 & 3 & 290.000 & 2 \\
\hline China & 270.000 & 2 & 290.000 & 2 \\
\hline Coreia & 250.000 & 2 & 230.000 & 2 \\
\hline Vietnã & 200.000 & 2 & 120.000 & 1 \\
\hline $\begin{array}{l}\text { República } \\
\text { Dominicana }\end{array}$ & 180.000 & 1 & 100.000 & 1 \\
\hline Outros países & 2.050 .000 & 17 & 2.220 .000 & 19 \\
\hline
\end{tabular}

Fonte: Baker (2017, p. 6).

O foco deste artigo são as recomendações realizadas justamente por esses Estados do chamado Triângulo Norte, além do México, que, tradicionalmente, é o país de origem de um grande número de migrantes ou é rota da migração para os EUA. Procuramos verificar, portanto, os comportamentos dos países de origem desses migrantes indocumentados na RPU do CDH especificamente dos EUA.

No tema específico da "contenção" dos fluxos migratórios, além de acordos bilaterais para tentar regular e/ ou deter tais fluxos (especialmente de indocumentados), a literatura apresenta outras estratégias mobilizadas pelos Estados, como a ajuda externa. Destacar isso neste trabalho tem um propósito metodológico. Terman e Voeten (2018) testam a interveniência da ajuda externa (a existência em si e a direção do fluxo de recursos entre Estado revisado e Estados revisores) como um dos parâmetros para verificar se Estados mantêm entre si uma relação de aliado ou não.

O debate entre questões migratórias e ajuda externa é vasto e muitas vezes a ajuda é vista por governos como uma estratégia para afastar a suposta ameaça que as migrações 
representam, securitizando o tema. Para esta chave de leitura, questões migratórias e de refúgio são capazes de influenciar as percepções de segurança de um determinado país (SaintPierre, 2011). Argumenta-se que o movimento de pessoas em larga escala pode criar conflitos, não somente no interior dos Estados, mas também entre Estados (Weiner, 1992, p. 94). Neste ambiente, a tendência dos formuladores de política externa e migratória é de acreditar que a grande parte desses fluxos migratórios ocorre devido a questões econômicas e que a ajuda externa, muitas vezes revestida de um viés humanitário, seria suficiente para conter esse fluxo na medida em que supostamente resolveria os problemas econômicos nos países de origem que motivam as migrações (Berthélemy, Beuran e Maurel, 2009). A literatura mostra que na relação entre migração e ajuda externa, em sentido amplo, o que se verifica é que o Estado estaria, de certa forma, disposto a pagar - em forma dessa ajuda, de investimentos, melhora nas trocas ou qualquer outra forma que contribua para o aumento do PIB e diminuição do desemprego - para evitar a migração (Weiner, 1992, p. 121).

Alguns estudos quantitativos, porém, tendem a demonstrar que em relação a países muito pobres, qualquer aumento do PIB gera o efeito contrário, aumentando a emigração desse país (Faini e Venturini, 1993). Já para países com economia relativamente ativa, a combinação de uma ajuda externa generosa com políticas migratórias austeras tornaria o custo de migrar muito alto e desestimularia a migração, mesmo que não contivesse totalmente o fluxo migratório (Berthélemy, Beuran e Maurel, 2009). Ao Estado doador restaria, então, usar estrategicamente a ajuda externa não para impedir a migração completamente, mas para moldar o fluxo migratório de forma a lhe ser mais benéfico (Clemens e Postel, 2017).

Os analistas do Congressional Research Service apontam que $47 \%$ da ajuda externa remetida durante o ano fiscal de 2018 para a região da América Latina e Caribe foi requisitada 
por meio do Fundo de Desenvolvimento e Apoio Econômico (ESDF). Essa rubrica é definida como a "ajuda consolidada que atualmente é oferecida pela Assistência ao Desenvolvimento (DA) e pelo Fundo de Apoio Econômico (ESF) para apoiar a democracia, o estado de direito, reformas econômicas, educação e a administração de recursos naturais" (Meyer, 2018). A rubrica disponibilizada pela DA faz referência a transformações econômicas e estabilidade social de longo prazo em países em desenvolvimento, enquanto as rubricas do ESDF e ESF focam em questões críticas que são consideradas objetivos estratégicos e de segurança estadunidenses. Outros 13\% foram destinados à região por meio de programas globais de saúde com o objetivo de apoiar programas de saúde gestacional, nutrição e combate à malária. Em conjunto, essas duas rubricas compõem $57 \%$ de toda ajuda externa destinada à região e seus objetivos podem ser vistos como passíveis de frear fluxos migratórios. Nesse contexto, os dados abaixo mostram a quantidade de ajuda externa remetida dos EUA para os países do hemisfério americano.

Tabela 6

Ajuda externa dos EUA para América Latina e Caribe por país ou por programa regional: ano fiscal (FY) 2013-2018 (valores em milhões de dólares)

\begin{tabular}{|c|c|c|c|c|c|c|c|}
\hline \multirow[b]{2}{*}{ Países } & \multicolumn{6}{|c|}{ Valor por ano } & \multirow{2}{*}{$\begin{array}{c}\% \\
\text { Mudança } \\
\text { FY2017- } \\
\text { FY2018 }\end{array}$} \\
\hline & 2013 & 2014 & 2015 & 2016 & 2017 & $\begin{array}{c}2018 \\
\text { (solicitado) }\end{array}$ & \\
\hline Argentina & 765 & 589 & 576 & 579 & 624 & 500 & $-20 \%$ \\
\hline Bahamas & 164 & 172 & 200 & 207 & 173 & 100 & $-42 \%$ \\
\hline Belize & 1,012 & 1,234 & 1,058 & 1,243 & 1,241 & 200 & $-84 \%$ \\
\hline Bolívia & 5,171 & 0 & 0 & 0 & 0 & 0 & - \\
\hline Brasil & 15,185 & 13,858 & 11,586 & 12,858 & 11,690 & 815 & $-93 \%$ \\
\hline Chile & 1,038 & 1,082 & 1,032 & 670 & 689 & 500 & $-27 \%$ \\
\hline Colômbia & 359,754 & 330,601 & 307,776 & 299,434 & 386,269 & 251,400 & $-35 \%$ \\
\hline Costa Rica & 1,624 & 1,731 & 1,673 & 1,819 & 5,718 & 400 & $-93 \%$ \\
\hline Cuba & 19,283 & 20,000 & 20,000 & 20,000 & 20,000 & 0 & $-100 \%$ \\
\hline
\end{tabular}


Tabela 6 (continuação)

\begin{tabular}{|c|c|c|c|c|c|c|c|}
\hline \multirow[b]{2}{*}{ Países } & \multicolumn{6}{|c|}{ Valor por ano } & \multirow{2}{*}{$\begin{array}{c}\% \\
\text { Mudança } \\
\text { FY2017- } \\
\text { FY2018 }\end{array}$} \\
\hline & 2013 & 2014 & 2015 & 2016 & 2017 & $\begin{array}{c}2018 \\
\text { (solicitado) }\end{array}$ & \\
\hline $\begin{array}{l}\text { República } \\
\text { Dominicana }\end{array}$ & 26,407 & 23,248 & 22,350 & 21,615 & 13,736 & 10,500 & $-24 \%$ \\
\hline Equador & 18,846 & 2,000 & 0 & 2,000 & 1,789 & 0 & $-100 \%$ \\
\hline El Salvador & 27,566 & 21,631 & 46,549 & 67,900 & 72,759 & 46,300 & $-36 \%$ \\
\hline Guatemala & 80,779 & 65,278 & 113,099 & 131,226 & 140,446 & 80,660 & $-43 \%$ \\
\hline Guiana & 9,150 & 6,904 & 4,692 & 243 & 277 & 200 & $-28 \%$ \\
\hline Haiti & 332,540 & 300,796 & 242,922 & 190,744 & 184,426 & 157,455 & $-15 \%$ \\
\hline Honduras & 51,980 & 41,847 & 71,191 & 98,250 & 95,260 & 67,850 & $-29 \%$ \\
\hline Jamaica & 7,061 & 6,670 & 5,573 & 5,065 & 10,597 & 500 & $-95 \%$ \\
\hline México & 265,064 & 206,768 & 165,168 & 160,156 & 138,566 & 87,660 & $-37 \%$ \\
\hline Nicarágua & 8,599 & 8,400 & 12,054 & 10,000 & 9,679 & 200 & $-98 \%$ \\
\hline Panamá & 3,449 & 2,986 & 4,077 & 3,346 & 3,271 & 1,200 & $-63 \%$ \\
\hline Paraguai & 6,041 & 7,528 & 7,980 & 8,620 & 6,150 & 400 & $-94 \%$ \\
\hline Peru & 98,634 & 82,649 & 84,079 & 74,898 & 64,473 & 49,691 & $-23 \%$ \\
\hline Suriname & 213 & 212 & 199 & 215 & 269 & 200 & $-26 \%$ \\
\hline $\begin{array}{l}\text { Trinidad e } \\
\text { Tobago }\end{array}$ & 167 & 179 & 308 & 325 & 343 & 160 & $-53 \%$ \\
\hline Uruguai & 427 & 725 & 550 & 499 & 498 & 400 & $-20 \%$ \\
\hline Venezuela & 5,786 & 4,298 & 4,256 & 6,500 & 7,000 & 0 & $-100 \%$ \\
\hline $\begin{array}{l}\text { Barbados } \\
\text { e Caribe } \\
\text { Oriental }\end{array}$ & 32,248 & 16,734 & 24,692 & 26,425 & 26,629 & 15,500 & $-42 \%$ \\
\hline Total & $1,684,470$ & $1,477,611$ & $1,584,840$ & $1,707,626$ & $1,710,059$ & $1,093,551$ & $-36 \%$ \\
\hline
\end{tabular}

Fonte: Adaptada pelos autores, a partir de Meyer (2018, p. 9).

Os dados sugerem haver uma relação entre o número de migrantes (especialmente de migrantes indocumentados) e os valores mais altos de ajuda externa (os casos de recebimento de alto volume de ajuda externa que fugiriam a essa relação seriam Haiti, em razão da sua grave e conhecida situação social, e a Colômbia, para a qual os EUA historicamente direcionam recursos robustos como parte 
da chamada "guerra às drogas"). Assim, observamos que a ajuda externa estadunidense voltada para a região direciona-se especialmente para México (ainda que em tendência de queda), Honduras, El Salvador e Guatemala (os três em visível tendência geral de ascensão, ainda que com oscilações episódicas). Os números do México, mesmo em tendência de queda, são representativos, tendo em vista a histórica tentativa de os EUA refrear a migração mexicana. Vale observar também como os países do Triângulo Norte, que estão crescentemente entre as principais origens de migrantes indocumentados nos EUA, receberam cada vez mais ajuda externa.

A hipótese inicial de Terman e Voeten (2018) era de que a existência de fluxos de ajuda externa poderia ser indicativa de uma relação de aliança entre os Estados envolvidos no referido fluxo. Como tal, esperava-se então que os países em questão, no ambiente da RPU, não fizessem muitas recomendações ao país revisado quando este Estado fosse a fonte da ajuda humanitária dos países revisores. Mais do que isso, a hipótese inicial dos autores é de que os Estados receptores de ajuda, quando fizessem recomendações, o fariam de forma branda, o que, por sua vez, aumentaria a tendência de aceitação pelo Estado emissor de ajuda humanitária.

Entretanto, depois de vários testes estatísticos gerais $\mathrm{e}$ específicos com as recomendações mais severas, Terman e Voeten (2018, pp. 17-18) notaram que a significância da ajuda externa como variável interveniente na dinâmica relacional da RPU não é necessariamente alta. É bom lembrar que os autores fizeram testes gerais e também testes com as recomendações mais severas, aquelas que demandam alterações visíveis de comportamento do Estado revisado. E é mais importante ainda lembrar que entre essas últimas a temática migratória é a mais contenciosa. Portanto, parece haver alguma dinâmica relacional específica com essa temática na RPU, tendo em vista sua peculiaridade contenciosa. 
Na próxima seção, o objetivo será, portanto, verificar o comportamento desses Estados do Triângulo Norte e do México enquanto Estados revisores na RPU dos EUA no tema das migrações. Veremos, em diálogo com o trabalho de Terman e Voeten (2018) - uma vez que esses Estados recebem grande parte da ajuda externa dos EUA na região e, portanto, se qualificariam, a priori, como aliados do país norte-americano - que as suas recomendações em matéria de migração não são, de fato, em menor número e mais brandas, dificultando a aceitação delas por parte dos EUA, contrariando a hipótese sistêmica de Terman e Voeten para a temática migratória. Esse afastamento das tendências generalizantes prescritas pelas hipóteses de Terman e Voeten aponta justamente para uma relação peculiar da temática migratória vinculada à presença significativa de migrantes indocumentados desses países nos EUA.

\section{A dinâmica política da questão migratória na RPU dos EUA: verificação das hipóteses relacionais}

Na presente seção empreenderemos uma comparação sistemática de modo a averiguar se as hipóteses de Terman e Voeten abrangentes da RPU como um todo são explicativas (1) dos dois ciclos de revisão pelos quais os EUA já passaram de modo geral e (2) especificamente das dinâmicas políticas da temática migratória durante esses ciclos.

A partir da caracterização de México, Guatemala, Honduras e El Salvador como aliados dos EUA, seguindo os parâmetros de Terman e Voeten, o que se espera é que, englobando todos os temas da RPU dos EUA, o México, a Guatemala, Honduras e El Salvador sejam países que fazem poucas recomendações.

Do grupo latino-americano, que é, junto do chamado grupo Ocidental, o grupo que mais faz recomendações aos EUA, com 24,55\% delas, Cuba é o que aparece mais ao topo da lista geral ( $3^{\circ}$ lugar com 19 recomendações no 
total), seguido da Nicarágua (em 10º com 13). El Salvador não será considerado para efeitos de verificação da hipótese, uma vez que esse país jamais fez recomendação alguma aos EUA sobre qualquer tema. Essa ausência de recomendações de El Salvador aos EUA é expressão da sua falta de engajamento com o mecanismo da RPU de modo mais sistêmico. Enquanto Guatemala e Honduras fizeram 423 e 355 recomendações respectivamente na história do mecanismo, El Salvador teceu apenas 56. O México fez 1.362.

Do total de recomendações feitas aos EUA englobando todos os temas, Guatemala, México e Honduras se encontram em posições mais baixas do ranking $\left(18^{\circ}, 35^{\circ}\right.$ e $74^{\circ}$, respectivamente), típicas de países aliados, já que, segundo Terman e Voeten, os não-aliados são os que mais recomendam. Ou seja, México e os países do Triângulo Norte não aparecem individualmente como principais revisores, confirmando a hipótese geral dos autores.

Tabela 7

Total de recomendações feitas aos EUA pelos países focos deste artigo

\begin{tabular}{|c|c|c|c|}
\hline Ranking & País & $\begin{array}{c}\text { Total de } \\
\text { recomendações }\end{array}$ & Porcentagem de recomendações \\
\hline 18 & Guatemala & 10 & $1,5 \%$ \\
\hline 35 & México & 7 & $1,05 \%$ \\
\hline 74 & Honduras & 3 & $0,45 \%$ \\
\hline
\end{tabular}

Fonte: Elaborada pelos autores, com os dados extraídos de UPR-Info (2018).

Entretanto, quando isolamos as recomendações sobre migrações, verificamos que o grupo é dos que mais fazem recomendações, estando, assim, no topo do ranking, não sendo possível confirmar a hipótese de Terman e Voeten neste caso, já que a condição de aliados dos EUA (ou pelo menos a condição de "não-não-aliado") não impediu esses países de serem aqueles que mais fazem recomendações em matéria de migração. 
Tabela 8

Análise percentual de recomendação dos países foco em relação ao tema das migrações. Total de recomendações aos EUA sobre migração: 60

$(8,98 \% \text { das } 688 \text { recomendações })^{8}$

\begin{tabular}{|c|l|c|c|c|}
\hline Ranking & $\begin{array}{c}\text { País } \\
\text { revisor }\end{array}$ & $\begin{array}{c}\text { Número total de } \\
\text { recomendações } \\
\text { feitas aos EUA }\end{array}$ & $\begin{array}{c}\text { Percentual de } \\
\text { recomendações } \\
\text { sobre migrações } \\
\text { feitas aos EUA em } \\
\text { relação ao total } \\
\text { recomendaçõóes migrações } \\
\text { feitas aos EUA } \\
\text { de recomendações } \\
\text { sobre migrações } \\
\text { recebidas pelos } \\
\text { EUA }\end{array}$ \\
\hline 1 & Guatemala & 10 & $7(70 \%$ do total) & $11,6 \%$ de 60 \\
\hline 3 & México & 7 & $3(42,85 \%$ do total) & $5 \%$ de 60 \\
\hline 3 & Honduras & 3 & $3(100 \%$ do total) & $5 \%$ de 60 \\
\hline
\end{tabular}

Fonte: Elaborada pelos autores, com os dados extraídos de UPR-Info (2018).

A segunda hipótese que precisamos testar refere-se ao nível de recusa das recomendações feitas pelos três países. Seguindo a hipótese de Terman e Voeten, uma vez que as recomendações desses países seriam supostamente mais brandas, elas tenderiam a ser mais aceitas pelo país norte-americano. Conforme pode-se ver na Tabela 9, México, Guatemala e Honduras não figuram nem entre os vinte países que mais tiveram recomendações recusadas pelos EUA.

Ao longo das duas revisões pelas quais os EUA já passaram na RPU em 2010 e 2015, o país recusou 310 recomendações. Dessas 310, apenas 9 correspondem aos três países aqui em questão, como pode-se ver na Tabela 10, ou seja, juntos eles representam somente 2,9\% das recomendações recusadas, confirmando sua condição aliada quando se observa todos os temas da RPU em conjunto, tal como apontado por Terman e Voeten.

\footnotetext{
8 Abaixo da Guatemala, na segunda posição do ranking está o Brasil, com quatro recomendações. O Egito também figura na terceira posição, empatado com México e Honduras, também com três.
} 
Tabela 9

Ranking com o número de recomendações recusadas por país

\begin{tabular}{|c|c|}
\hline País & Total de recomendações recusadas \\
\hline Venezuela & 18 \\
\hline Cuba & 11 \\
\hline Coreia do Norte & 9 \\
\hline Egito & 9 \\
\hline Nicarágua & 9 \\
\hline Rússia & 9 \\
\hline Noruega & 7 \\
\hline Irã & 7 \\
\hline França & 7 \\
\hline Bolívia & 7 \\
\hline Áustria & 7 \\
\hline Espanha & 6 \\
\hline Paquistão & 6 \\
\hline Alemanha & 6 \\
\hline Equador & 6 \\
\hline Suíça & 5 \\
\hline Maldivas & 5 \\
\hline Gana & 5 \\
\hline Dinamarca & 5 \\
\hline China & 5 \\
\hline Bélgica & 5 \\
\hline$[\ldots]$ & {$[\ldots]$} \\
\hline Honduras & 3 \\
\hline Guatemala & 4 \\
\hline México & 2 \\
\hline
\end{tabular}

Fonte: Elaborada pelos autores, com os dados extraídos de UPR-Info (2018).

Entretanto, a dinâmica se modifica quando observamos especificamente o tema migratório. Conforme a Tabela 11, as recomendações sobre migrações desses três países tendem a não serem aceitas pelos EUA, contrariando a hipótese generalista de Terman e Voeten e confirmando, de certa forma, o achado estatístico dos mesmos autores a respeito da natureza peculiarmente contenciosa da temática migratória. 
A não aplicabilidade da hipótese generalista dos autores para esse caso específico fica ainda mais visível quando observamos que Honduras, Guatemala e México ocupam o topo da lista de recomendações recusadas pelos EUA atinentes ao tema das migrações. A hipótese não é, mais uma vez, verificável, pois nesse tema os três países figuram entre os que mais tiveram recomendações recusadas, a despeito de não serem países geopoliticamente oponentes dos EUA.

Tabela 10

Total de recomendações dos países foco deste estudo recusadas pelos EUA em relação ao total de recusas. Total de recomendações recusadas pelos EUA: 310

\begin{tabular}{|l|c|c|c|}
\hline \multicolumn{1}{|c|}{ País } & $\begin{array}{c}\text { Total de } \\
\text { recomendações } \\
\text { recusadas }\end{array}$ & $\begin{array}{c}\text { Total de } \\
\text { recomendações } \\
\text { recusadas sobre } \\
\text { migrações }\end{array}$ & $\begin{array}{c}\text { Porcentagem de } \\
\text { recomendações recusadas } \\
\text { em relação ao total }\end{array}$ \\
\hline Guatemala & 4 & 2 & $1,29 \%$ \\
\hline México & 2 & 2 & $0,64 \%$ \\
\hline Honduras & 3 & 3 & $0,96 \%$ \\
\hline
\end{tabular}

Fonte: Elaborada pelos autores, com os dados extraídos de UPR-Info (2018).

Alguns dados reforçam ainda mais nosso argumento. Como referido, as recomendações de México, Guatemala e Honduras representam juntas apenas 2,9\% das 310 já recusadas pelos EUA nos ciclos da RPU. O mesmo raciocínio aplicado especificamente ao tema migratório nos traz números bem diferentes. Até hoje, os EUA recusaram 20 das 60 recomendações relativas especificamente a migrações. Dessas 20, 7 são recomendações dos três países em questão, ou seja, representam juntas $35 \%$ de todas as recomendações já recusadas pelos EUA em matéria migratória. Apenas para efeitos comparativos de ilustração, os três países que ocupam o topo da lista das recusas em geral (Venezuela, Cuba e Coreia do Norte, países notadamente não-aliados dos EUA) juntos perfazem apenas 12,25\% de todas as recusas. 
Tabela 11

Total de recomendações sobre migrações dos países foco deste estudo recusadas pelos EUA em relação ao total de recusas. Total de recusas dos EUA no tema das migrações: 20

\begin{tabular}{|c|c|c|c|}
\hline Ranking & País & $\begin{array}{c}\text { Quantidade de } \\
\text { recomendações } \\
\text { recusadas }\end{array}$ & $\begin{array}{c}\text { Porcentagem das recomendações } \\
\text { recusadas diante do total de } \\
\text { recusas (20) }\end{array}$ \\
\hline 1 & Honduras & 3 & $15 \%$ \\
\hline 2 & Guatemala & 2 & $10 \%$ \\
\hline 2 & México & 2 & $10 \%$ \\
\hline
\end{tabular}

Fonte: Elaborada pelos autores, com os dados extraídos de UPR-Info (2018).

Verificamos, ainda, se esses países apareceriam com um nível proporcional de aceitação igual ou acima do nível geral de aceitação de recomendações pelos EUA. Espera-se que um país aliado apresente um nível de aceitação acima da média. Da totalidade das recomendações somados os dois ciclos, os EUA aceitaram 358 (de 688), o que significa que sua média de aceitação é de $53,59 \%$. Um país que seja aliado dos EUA, como são Guatemala, México e Honduras, deverá ter possivelmente uma taxa média de aceitação de recomendações acima de 53,59\%.

Tabela 12

Proporção de recomendações aceitas em geral pelos EUA com foco nos países deste estudo

\begin{tabular}{|c|c|c|}
\hline País & $\begin{array}{c}\text { Recomendações aceitas } \\
\text { em geral }\end{array}$ & $\begin{array}{c}\text { Análise percentual em relação ao } \\
\text { total de aceitação dos EUA }\end{array}$ \\
\hline Guatemala & $6(6$ de $10-60 \%)$ & Acima de $53,59 \%$ \\
\hline México & $5(5$ de $7-71,42 \%)$ & Acima de $53,59 \%$ \\
\hline Honduras & $0(0$ de $3-0 \%)$ & Abaixo de $53,59 \%$ \\
\hline
\end{tabular}

Fonte: Elaborada pelos autores, com os dados extraídos de UPR-Info (2018).

Quando observamos todos os temas em conjunto, a hipótese geral de Terman e Voeten é confirmada novamente, pois tanto Guatemala quanto México apresentam índices de aceitação acima de 53,59\%, 60\% e 71,42\%, 
respectivamente. Ao primeiro olhar, chama a atenção os números de Honduras, que teve suas três recomendações recusadas, contrariando a hipótese geral dos autores. Mas só se compreende isso quando se observa que as três recomendações de Honduras se referem justamente a questões de migração, confirmando o achado estatístico de Terman e Voeten e nosso argumento de que o tema migratório se comporta de maneira peculiar, contenciosa e não é coberto pela explicação generalizante de Terman e Voeten.

Das 60 recomendações específicas sobre migrações recebidas pelos EUA nos dois ciclos da RPU, 40 foram aceitas. Isso resulta, assim, em uma taxa média de $66,66 \%$ de aceite. Espera-se que os países aliados tenham uma taxa de aceitação de recomendações acima de 66,66\%. Tal como visto, Honduras tem taxa zero de aceitação em matéria migratória. O México apresenta também uma taxa de aceitação abaixo daquela que se esperaria que um país aliado, em termos gerais, apresentasse: $33,33 \%$. Ao isolarmos, portanto, as recomendações sobre migrações, a tendência de aceitação é invertida em relação àquela que se extrai das explicações de Terman e Voeten. Neste caso, a Guatemala é o único país que mantém a tendência, pois apresenta uma taxa de aceitação de 71,42\% em temática migratória, o que merecerá futuramente um estudo de caso mais detido, pois será preciso analisar especificamente o conteúdo e o sentido das suas recomendações.

Tabela 13

Proporção de recomendações aceitas pelos EUA sobre migrações com foco nos países de estudo. Totais para migração: 40 aceites $(66,66 \%$ de 60$)$

\begin{tabular}{|c|c|c|}
\hline País & $\begin{array}{c}\text { Total de recomendações aceitas em } \\
\text { relação a migrações }\end{array}$ & $\begin{array}{c}\text { Análise em relação } \\
\text { ao total }\end{array}$ \\
\hline Guatemala & $5(5$ de $7-71,42 \%)$ & Acima de $66,66 \%$ \\
\hline México & $1(1$ de $3-33,33 \%)$ & Abaixo de $66,66 \%$ \\
\hline Honduras & $0(0$ de $3-100 \%)$ & Abaixo de $66,66 \%$ \\
\hline
\end{tabular}

Fonte: Elaborada pelos autores, com os dados extraídos de UPR-Info (2018). 


\section{Considerações finais}

Este texto integra uma agenda de pesquisa mais ampla com o intuito de compreender a participação dos EUA no mecanismo da RPU sob diferentes ângulos e temas. Este artigo esforçou-se para analisar uma temática específica: a migratória. A escolha dessa temática não se justificou apenas pela alta relevância histórica e atual que ela tem na política dos EUA. Ela se justifica também metodologicamente por fornecer uma oportunidade de testar uma hipótese sobre a RPU em um tema que oferece uma complexidade adicional à já sempre sensível agenda internacional de direitos humanos no plano global e para os EUA especificamente. Essa complexidade adicional tem a ver com o fato de a RPU possibilitar que os Estados revisores, como México, Guatemala e Honduras, se pronunciem não só a respeito de como os EUA tratam os cidadãos norte-americanos, mas também os migrantes que estão nos EUA, como mexicanos, guatemaltecos e hondurenhos, documentados ou não.

Este artigo aponta para a confirmação da hipótese de Terman e Voeten acerca do funcionamento sistêmico da RPU, mas também parece mostrar que essa hipótese não é necessariamente explicativa dos debates específicos. Nossa discussão aqui sugere que a variável determinante entre Estado revisado e Estados revisores na dinâmica relacional da RPU, no caso da matéria migratória, é a questão da grande presença de migrantes em território estadunidense, especialmente dos indocumentados. Conforme observado, a ajuda externa é mobilizada pelo Estado receptor na tentativa de conter ou moldar o fluxo migratório, especialmente aquele advindo de países com maior incidência de migrantes indocumentados.

Há aí, portanto, uma importante diferença entre o papel metodológico exercido pela ajuda externa no modelo explicativo generalista de Terman e Voeten e o papel que ela exerce quando se circunscreve a análise apenas à 
temática migratória. A presença de fluxo significativo de ajuda externa no modelo de Terman e Voeten é, de início, um potencial indicativo de relação de aliança entre Estado revisor e Estado revisado. Como tal, a partir da constatação dessa presença desencadear-se-ia no âmbito da RPU um padrão de relação típico de Estados aliados. Entretanto, os próprios autores, depois de vários testes estatísticos, admitem que a significância da ajuda externa como variável interveniente na dinâmica relacional da RPU é incerta.

Este estudo mostra, de certa forma, as razões qualitativas dessa incerteza. Quando a análise se detém à temática migratória na RPU, a presença de fluxo significativo de ajuda externa do país revisado para o país revisor (como ocorre entre EUA e o México e os países do Triângulo Norte) é provável indício de que o Estado revisado esteja tentando "conter" o fluxo migratório, notadamente de indocumentados, para dentro de suas fronteiras, e não zelando por uma relação de aliança primordialmente. $O$ estoque de ajuda externa, portanto, não é indicativo de aliança nesse caso, mas sim indicativo de que esses Estados guardam uma relação de tensão em razão justamente da migração indocumentada, altamente estigmatizada em países receptores e frequente motivo de restrição de acesso a direitos. Foi justamente isso que mostrou a nossa análise da relação entre EUA, enquanto país revisado na RPU, e México, Guatemala e Honduras: esses países são responsáveis por parte importante das recomendações sobre migrações na RPU dos EUA e estão no topo dos países com mais recusas pelos norte-americanos quando se trata dessa temática.

A tentativa de operacionalização das hipóteses sistêmicas de Terman e Voeten sobre a RPU em uma temática mais circunscrita parece não apenas evidenciar a dificuldade do modelo generalizante se aplicar a casos específicos e a relativa inadequação das suas variáveis amplas como ajuda externa - para classificar as relações mantidas 
por Estado revisado e Estados revisores na RPU. Mais que isso, essa tentativa mostrou como a lógica aliado $\times$ não-aliado não tem potencial explicativo e preditivo quando se trata de uma temática mais específica da RPU. Assim, quando a lente metodológica se afasta do nível sistêmico e se aproxima mais de um fenômeno específico (pelo menos no caso do fenômeno migratório, peculiarmente contencioso, como evidenciado diversas vezes ao longo do texto e corroborando com os achados estatísticos de Terman e Voeten), a questão determinante na RPU não parece ser tanto a lógica da aliança perene, mas muito mais a presença ou ausência dinâmica de interesses divergentes dos Estados revisores em relação ao Estado revisado, no caso aqui, os EUA. É com essa consciência, portanto, da aproximação da lente metodológica, que a presença de alto número de migrantes indocumentados do México e dos países do Triângulo Norte nos EUA torna-se uma variável muito mais determinante na dinâmica dos temas migratórios na RPU do que o fluxo de ajuda humanitária, como preconizava inicialmente a explicação de Terman e Voeten.

Quando a análise se descola da díade aliado × não-aliado, a compreensão que se tem da própria RPU também se modifica. A díade é adequada para se pensar a dinâmica do constrangimento, do shaming, pois prevê-se que um país não tencione constranger seu aliado, enquanto um não-aliado não teria problemas em fazê-lo. Portanto, a condição de aliança seria o critério para produção de shaming. A discussão sobre a temática migratória, no entanto, mostrou a RPU por outro ângulo, como uma oportunidade política institucionalmente normatizada da qual os Estados podem se valer para, mais do que constranger ou criticar, explicitar seus interesses e agendas diante de atores poderosos. Nesse sentido, a retirada dos EUA do CDH pelo governo Trump em junho de 2018 ganha traços ainda mais graves, pois, mais do que vedar um espaço no qual os EUA sofriam constrangimentos internacionais, 
a retirada inviabiliza uma oportunidade política dos Estados exercerem diplomacia pública em defesa de seus interesses diante dos EUA. Fecha-se, portanto, um canal de diálogo público e multilateral sobre direitos humanos com o país norte-americano, restando a muitos Estados apenas a dinâmica bilateral longe dos holofotes, em que as normas têm menos alcance e as assimetrias de poder exercem um papel ainda mais preponderante.

Apesar deste artigo ter avançado alguns argumentos, há ainda uma agenda de pesquisa a ser percorrida para uma análise mais completa da temática migratória na RPU dos EUA. Nosso próximo passo será explorar, de forma mais detida e qualitativa, o teor e o sentido tanto das recomendações feitas pelos três países (e por outros) aos EUA quanto das recusas apresentadas pelos norte-americanos. Isso contribuirá para tentar compreender, por exemplo, o caso específico da Guatemala, que, apesar de fazer várias recomendações sobre migrações aos EUA, tem taxa de aceitação acima da média. Possivelmente a explicação irá se relacionar com o tipo específico de relações diplomáticas bilaterais mantidas entre os dois países, inclusive no âmbito da ONU e da RPU, e com o conteúdo das recomendações guatemaltecas, as quais podem ter sido formuladas de forma demasiadamente brandas, facilitando a aceitação pelos EUA.

Um outro possível passo a se explorar é o aprofundamento do teste das explicações de Terman e Voeten, acrescentando outras variáveis que os autores utilizam para identificação de relação de aliança: afinidade geopolítica, aliança militar formalizada e comércio de armas. Ainda que sejam variáveis complexas, nossa hipótese, a respeito da dinâmica relacional da temática migratória dos EUA com os países revisores, é de que tais variáveis não serão mais decisivas do que a presença de migrantes indocumentados nos EUA. 


\section{Matheus de Carvalho Hernandez}

é professor de Relações Internacionais na Universidade Federal da Grande Dourados, com estágio pós-doutoral no Institute for the Study of Human Rights da Columbia University. Pesquisador do Instituto Nacional de Ciência e Tecnologia para estudos para estudos sobre os Estados Unidos (INCT-Ineu).

\section{William Torres Laureano da Rosa}

é professor do Programa de Pós-Graduação em Relações Internacionais San Tiago Dantas. Doutor em Relações Internacionais pela University of Sussex e pesquisador do Instituto Nacional de Ciência e Tecnologia para Estudos sobre os Estados Unidos (UNESP/UNICAMP/PUC-SP).

\section{Bibliografia}

BAKER, Bryan. 2017. Estimates of the unauthorized immigrant population residing in the United States: January 2014. United States: DHS Office of Immigration Statistics.

BEARCE, David. H.; BONDANELLA, Stacy. 2007. Intergovernmental organizations, socialization, and member-state interest convergence. International Organizations, v. 61, n. 4, pp. 703-733.

BERTHÉLEMY, Jean-Claude; BEURAN, Monica; MAUREL, Mathilde. 2009. Aid and migration: substitutes or complements? World Development, v. 37, n. 10, pp. 1589-1599.

CANADA: IMMIGRATION AND REFUGEE BOARD OF CANADA. 2018. Haiti and United States: whether legal representation is required for persons who apply for asylum in the US; availability of legal aid for asylum applicants, particularly for Haitians, in the states of California, Florida, New Jersey and New York. Disponível em: http://www.refworld.org/docid/5b615d794. html. Acesso em: 6 jun. 2018.

CLEMENS, Michael A.; POSTEL, Hannah M. 2017. Deterring emigration with foreign aid: an overview of evidence from low-income countries.

Washington, DC: Center for Global Development.

DEPARTMENT OF HOMELAND SECURITY. 2018. Table 2: persons obtaining lawful permanent resident status by region and selected country of last residence: Fiscal years 2015 to 2017. Disponível em: https://www.dhs.gov/ immigration-statistics/yearbook/2017/table2. Acesso em: 30 set. 2019. 
FAINI, Riccardo; VENTURINI, Alessandra. 1993. Trade, aid and migrations: some basic policy issues. European Economic Review, v. 37, n. 2-3, pp. 435-442.

FINNEMORE, Martha. 1993. International organizations as teachers of norms: The United Nations Educational, Scientific, and Cultural Organization and science policy. International Organization, v. 47, n. 4, pp. 565-597.

FORSYTHE, David. 2011. US foreign policy and human rights: situating Obama. Human Rights Quarterly, v. 33, n. 3, pp. 767-789.

FREEDMAN, R. 2015. Failing to protect: the UN and the politicisation of human rights. Oxford: New York.

GARCÍA, Jacobo. 2019. Nova caravana põe em alerta Estados Unidos, México e América Central. El País, 15 jan. Disponível em: https://brasil.elpais.com/brasil/2019/01/14/ internacional/1547432841_627007.html. Acesso em: 16 jan. 2019. GLOBAL DETENTION PROJECT. 2010. Immigration detention and the law: US policy and legal framework. Geneva: Programme for the Study of Global Migration.

HASENCLEVER, Andreas; MAYER, Peter; RITTBERGER, Volker. 1997. Theories of international regimes (Cambridge Studies in International Relations). Cambridge: Cambridge University Press.

HERNANDEZ, Matheus de Carvalho. 2013. Direitos humanos e política externa norte-americana: a participação dos EUA na Conferência de Viena (1993). Brazilian Journal of International Relations, v. 2, n. 2, pp. 330-351.

HERNANDEZ, Matheus de Carvalho. 2017a. O cartão amarelo de Trump para o Conselho de Direitos Humanos da ONU. Nexo, 8 ago. Disponível em: https:/ / www.nexojornal.com.br/ensaio/2017/O-cartão-amarelode-Trump-para-o-Conselho-de-Direitos-Humanos-da-ONU. Acesso em: 22 nov. 2018.

HERNANDEZ, Matheus de Carvalho. 2017b. Os Estados Unidos e as negociações sobre a criação do posto de Alto Comissário para Direitos Humanos da ONU. Revista Esboços, v. 24, n. 38, pp. 286-314.

HERNANDEZ, Matheus de Carvalho. 2018. O cartão vermelho de Trump para o Conselho de Direitos Humanos da ONU. Estadão - Blog Fausto Macedo, 20 jun. Disponível em: https://politica.estadao.com.br/ blogs/fausto-macedo/o-cartao-vermelho-de-trump-para-o-conselho-dedireitos-humanos-da-onu/. Acesso em 23 nov. 2018.

HERNANDEZ, Matheus de Carvalho; ROSA, William Torres Laureano da. 2011. Excepcionalismo americano e as violações de direitos humanos no pós-11 de setembro. Carta Internacional, v. 6, n. 1, pp. 101-113. 
HERNANDEZ, Matheus de Carvalho; ROSA, William Torres Laureano da. 2018. Os EUA e a revisão periódica universal do Conselho de Direitos Humanos da ONU. Estudos Internacionais, v. 6, n. 1, pp. 127-149. HERNANDEZ, Matheus de Carvalho; ALBRES, Hevellyn; MACEDO, Gustavo. 2013. De Bush a Obama: a dotação orçamentária dos EUA para o Conselho de Direitos Humanos da ONU. Carta Internacional, v. 8, n. 1, pp. 131-150.

INTER-AMERICAN COMMISSION ON HUMAN RIGHTS. 2010. Report on immigration in the United States: detention and due process. San José: InterAmerican Commission on Human Rights.

INTERNATIONAL ORGANIZATION FOR MIGRATION. 2018. World Migration Report 2018. Geneva: International Organization for Migration. Disponível em: https://publications.iom.int/system/files/ pdf/wmr_2018_en.pdf. Acesso em: 22 abr. 2019.

JAKOBI, Anja. P. 2009. International organizations and lifelong learning: from global agendas to policy diffusion. Basingstoke: Palgrave Macmillan.

JOHNSON, Kevin R. 2000. Immigration, citizenship, and US/Mexico relations: the tale of two treaties. Bilingual Review/La Revista Bilingüe, v. 25, n. 1, pp. 23-38.

MEYER, Peter J. 2018. US Foreign assistance to Latin America and the Caribbean: FY2018 Appropriations. United States: Congressional Research Service. Disponível em: https://fas.org/sgp/crs/row/R45089.pdf. Acesso em: 30 set. 2019.

RADFORD, Jynnah; NOE-BUSTAMANTE, Luis. 2019. Facts on US Immigrants, 2017. Pew Research Center, 3 jun. Disponível em: http://www.pewhispanic.org/2018/09/14/facts-on-u-s-immigrants/. Acesso em: 30 set. 2019.

ROJAS, A. Gabriela. 2018. A chegada da caravana de migrantes à fronteira dos EUA: "Não nos querem aqui, fomos recebidos com pedras". $B B C$ Brasil, 19 nov. Disponível em: https://www.bbc.com/portuguese/ internacional-46258863. Acesso em: 22 nov. 2018.

ROLDÁN, Genoveva. 2015. Migration from Mexico to the United States: the renewed liberal paradox of Nafta. Problemas del Desarrollo, v. 46, n. 181, pp. 101-126.

SAINT-PIERRE, Héctor Luis. 2011. "Defesa" ou "segurança"?: reflexões em torno de conceitos e ideologias. Contexto Internacional, v. 33, n. 2, pp. 407-433.

SELEE, Andrew. 2017. A new migration agenda between the United States and Mexico: charting a new course: policy options for the next stage in U.S.-Mexico relations. Washington, DC: Wilson Center. Disponível em: 
https://www.wilsoncenter.org/sites/default/files/a_new_migration_ agenda_between_the_united_states_and_mexico.pdf. Acesso em: 14 out. 2018.

TERMAN, Rochelle; VOETEN, Erik. 2018. The relational politics of shame: evidence from the universal periodic review. The Review of International Organizations, v. 13, n. 1, pp. 1-23.

UN HUMAN Rights Council should strengthen impact on the ground. 2018. Human Rights Watch, Genebra, 23 abr. Disponível em: https://www.hrw.org/news/2018/04/23/un-human-rights-councilshould-strengthen-impact-ground. Acesso em: 6 jun. 2018.

UPR-INFO. 2018. [Dados estatísticos sobre direitos humanos]. Disponível em: https://www.upr-info.org/en. Acesso em: 29 set. 2019.

US AND MEXICO child deportations drive extreme violence and trauma: Unicef. 2018. UN News Service, 16 ago. Disponível em: http://www. refworld.org/docid/5bc4951da.html. Acesso em: 19 out. 2018.

VILLARREAL, Andrés. 2014. Explaining the decline in Mexico-US migration: the effect of the great recession. Demography, v. 51, n. 6, pp. 2203-2228.

WEINER, Myron. 1992. Security, stability, and international migration. International Security, v. 17, n. 3, pp. 91-126. 